\title{
Max Ferdinand Perutz - Lord Hemoglobina -
}

\author{
Raquel Gonçalves Maia ${ }^{1}$ \\ Departamento de Química e Bioquímica, Faculdade de Ciências da Universidade de Lisboa \\ rmcgonc@gmail.com
}

Max Ferdinand Perutz - Lord Hemoglobin - The "How can I solve the secret of life?", asks Maximilian (Max) Ferdinand Perutz, a PhD student at the Cavendish Laboratory, born in Vienna. He thinks, and chooses hemoglobin as the object of study. He performed one of the greatest contributions to science in the twentieth century.

He devoted more than twenty years to the discovery of the three-dimensional structure of the hemoglobin molecule. Then, to the exploration of border areas: biomechanical, biophysical and biochemical functions; and to the hemoglobin anomalies, which allowed medical and pharmacological success. He was awarded the Nobel Prize in Chemistry (1962), which he shared with John Kendrew.

Perutz did not have an easy life. The World War II turned the student into a refugee and, then, into an enemy and a prisoner. He never became discouraged. Gisela Peiser and their children offered him always hegemony and emotional security.

Max Perutz was an educated man. He liked literature, classical music and art. He liked to climb mountains and uncover secrets of glaciers. His word captivated audiences. He was jealous of "his" hemoglobin. He was founder and chairman of the MRC Laboratory of Molecular Biology in Cambridge, where he introduced the enabling environment for scientific development.

“C

Como posso desvendar o segredo da vida?”, pergunta Maximilian (Max) Ferdinand Perutz, estudante de doutoramento no Laboratório Cavendish, nascido em Viena. Pensa, e elege a hemoglobina como objeto de estudo. Protagonizou uma das maiores contribuições para a ciência do século XX.

Foram mais de vinte anos dedicados à descoberta da estrutura tridimensional da molécula da hemoglobina. Depois, à exploração de zonas de fronteira: funções biomecânicas, biofísica e bioquímica; e às anomalias da hemoglobina, que permitiram o sucesso médico e farmacológico. Recebeu o Prémio Nobel da Química em 1962, que partilhou com John Kendrew.

Perutz não teve uma vida fácil. A Segunda Guerra Mundial transformou o estudante em refugiado e, logo, em inimigo e prisioneiro. Nunca soçobrou. Gisela Peiser e os seus filhos ofereceram-lhe sempre primazia e segurança emocional.

Max Perutz era um homem culto. Gostava de literatura, música clássica e arte. Gostava de escalar montanhas e desvendar segredos dos glaciares. A sua palavra cativava audiências. Era cioso da "sua" hemoglobina. Foi fundador e chairman do MRC Laboratory of Molecular Biology em Cambridge, onde introduziu o ambiente propiciador ao desenvolvimento científico.

\section{Em Viena de Áustria}

O químico Max Perutz nasceu em Viena em 19 de maio de 1914, filho do casal Hugo Perutz e Adele Goldschmidt, "Dely". O pai nascera em Praga, de ascendência judaica, e a mãe era austríaca. A família dispunha de bons recursos e um estatuto de classe privilegiada. Max e os seus dois irmãos frequentaram boas escolas, aprenderam piano, francês e inglês.

Max foi uma criança reservada, que encontrava nos livros a companhia e o estímulo intelectual; e nos esquis, enquanto deslizava sobre a neve e sonhava o futuro. Desabrochou pelos 16 anos. Recebe as primeiras aulas de química e assim escreverá mais tarde: "A mistura dos produtos químicos, todas aquelas cores maravilhosas, realmente fascinaram-me" [1-3]. Esperava-se que Max estudasse leis, a fim de assumir a sua quota-parte nos negócios familiares [4]. A decisão, porém, estava tomada: depois do ensino secundário, a Universidade de Viena e o curso de quí-

Professora Catedrática aposentada

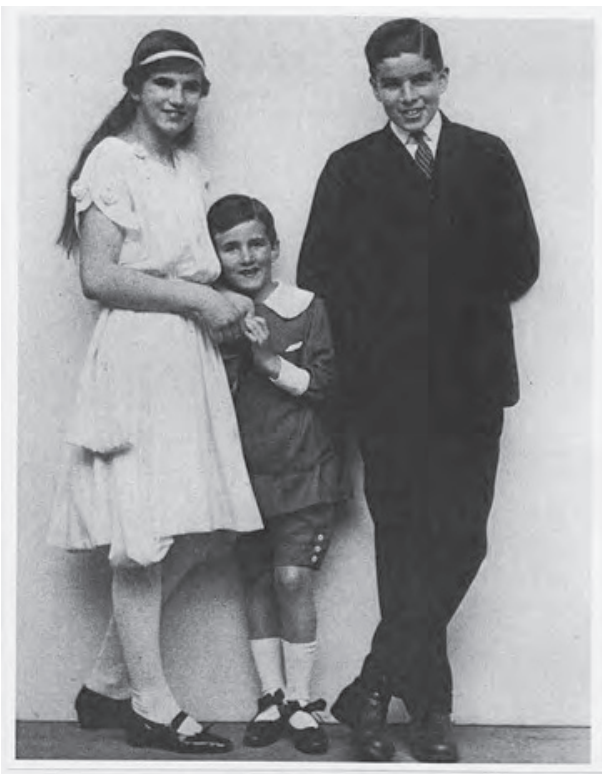

Figura 1 - Max entre os irmãos Lotte e Franz ( 1920$)$. Cortesia de Vivien Perutz. 
mica. Foi difícil convencer os pais, mas Max contou com a ajuda de Friedrich (Frederick) Eirich (1905-2005), que lecionava na Universidade. Foi ainda com a ajuda do mesmo que foi transmitido a Desmond Bernal (1901-1971) que havia em Viena "um estudante graduado para ele”. Bernal, o "Sage”, dirigia o laboratório de cristalografia do Laboratório Cavendish, sob a supervisão suprema de Lawrence Bragg (1890-1971; Prémio Nobel da Física em 1915) [5,6]. Max Perutz partiu, rumo à Universidade de Cambridge. Levava consigo uma boa dose de ambição científica, uma considerável quantia no bolso e um conjunto apropriado de fatos para os jantares formais...

\section{Os primeiros cristais}

“Como posso desvendar o segredo da vida?”, perguntou Max a Desmond Bernal. "O segredo da vida está na estrutura das proteínas, e a forma de o conseguir é através de cristalografia de raios X”, respondeu-lhe este. Bernal, se não estava totalmente certo, também não estava totalmente errado. A inexperiência de Perutz sobre a temática, teórica e prática, moderou os primeiros desafios. Analisou cristalograficamente um composto metálico, o mineral rodonite. E agora? Agora, esperava-se que fosse o próprio doutorando a sugerir a temática a desenvolver.

Nas férias de verão de 1937, Max retorna à sua terra natal. A família, Viena e as suas montanhas... Tem tempo para pensar. Decide conversar com o médico e bioquímico, então professor na Universidade Alemã de Praga, Felix Haurowitz (1896-1987), seu primo por afinidade. Desde 1925 que Haurowitz estudava a fisiologia da hemoglobina, a metaloproteína que contém ferro e que está presente nos glóbulos vermelhos.

De regresso a Cambridge, partilhou com Bernal a decisão tomada: a sua molécula "mistério" seria a da hemoglobina; propunha-se investigar a estrutura tridimensional da molécula, determinar dimensão e ângulo das ligações entre os seus átomos, e talvez mesmo decifrar a relação entre a estrutura e a sua função distribuidora de oxigénio. Até então, a molécula orgânica mais complexa cuja estrutura fora decidida por cristalografia de raios $\mathrm{X}$ tinha pouco mais do que cinquenta átomos. Quereria Max localizar espacialmente as várias centenas, milhares (!), que compunham a molécula da hemoglobina? "Max, deves estar louco!”.

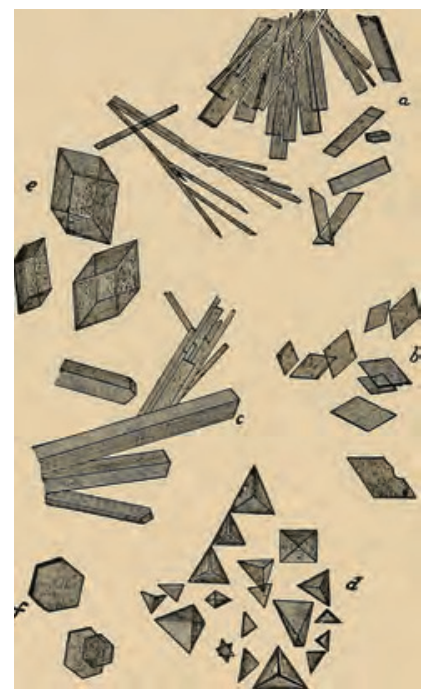

Figura 2 - Cristais de hemoglobina do sangue: a, b - homem; c - gato; d - porquinho-da-índia; e - hamster; f - esquilo (Howell, W.H., "A text-book of Physiology for Medical Students and Physicians”, W.B. Saunders, 4 . $^{\text {e ed., pág. }}$ 422, 1911).
Mas, se Max era "louco”, Bernal não lhe ficava atrás. Era preciso começar por obter cristais...

Contactado por Bernal, o fisiologista (Abdul) Gilbert Adair (1896-1979) obteve cristais de metemoglobina [7] de cavalo e, generosamente, ofereceu-os a Max Perutz. Após prolongado tratamento, surgiram cristais bem formados e grandes $(0,5 \mathrm{~mm})$ que foram submetidos aos raios $\mathrm{X}$; apresentaram um comportamento muito satisfatório. A intensidade, posição e regularidade das manchas dos diagramas obtidos indicavam a possibilidade de se poder estabelecer um modelo estrutural. Com a preciosa ajuda de Bernal e do norte-americano Isidor Fankuchen (1904-1964), à época seu assistente, emergiu a primeira resposta sobre a hemoglobina: a dimensão da célula unitária, contendo duas moléculas [8]. As condições técnicas e metodológicas disponíveis, todavia, não permitiam ir mais longe. A completa decifração da molécula da hemoglobina teria de esperar.

Entretanto, em 1937-1938, Desmond Bernal aceita o convite da Universidade de Londres para ocupar a cátedra de física no conceituado Birkbeck College. Uma amistosa conversa assegurou a "supervisão" de Max por Lawrence Bragg e o aconselhamento científico permanente de Bernal.

\section{Perutz glaciologista}

O reputado glaciologista Gerald Seligman (1886-1973) preparava uma expedição para o verão de 1938 ao Jungfraujoch, no “topo da Europa” (Suíça). Seligman queria levar consigo alguém que esquiasse bem e percebesse de cristais - Max Perutz, evidentemente.

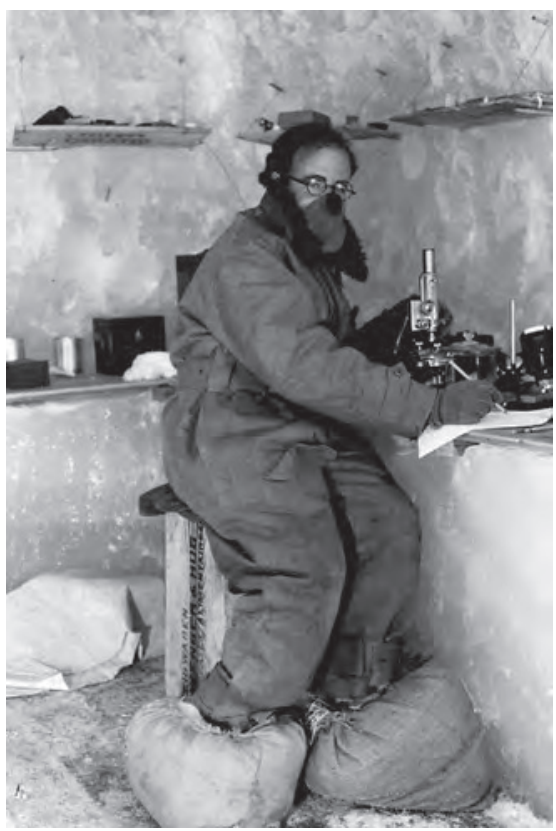

Figura 3 - Max Perutz na sua caverna de gelo no Jungfraujoch. Cortesia de Vivien Perutz.

Perutz criou um laboratório apropriado numa caverna de gelo. Protege nariz e boca a fim de evitar que o hálito escureça a ocular do microscópio, enquanto sacos cheios de feno lhe conservam o calor nos pés.

Mais tarde, em 1948, Perutz empenhou-se numa nova expedição, igualmente liderada por Seligman, dedicada ao estudo dos fluxos glaciares junto da Jungfraujoch Research Station. Foi o primeiro estudo experimental sobre o com- 
portamento do gelo, superficial e de profundidade, de um glaciar, tema que virá a ser posteriormente desenvolvido nos glaciares dos Alpes, e também da Gronelândia e do Alasca, tendo em conta os efeitos do aquecimento global. Útil e fascinante.

Em seguida, Max Perutz recebe um honroso convite para integrar, na qualidade de "glaciologista sénior", uma expedição à Antártida (1948-1950) num contexto internacional (britânico, norueguês e sueco). Em 1953, convite idêntico levá-lo-ia às Canadian Rockies. Contudo, consciente das implicações familiares e do impacto na pesquisa química, não aceita. Perutz deu por terminadas as suas pesquisas sobre gelos e glaciares, mas não o seu amor pelas montanhas.

\section{Tempos de guerra}

Nem a hemoglobina, nem as expedições ao Jungfraujoch, contudo, eram as únicas preocupações de Perutz. Hitler anexara a Áustria em março de 1938. Max Perutz tornara-se, subitamente, um refugiado no Reino Unido. O seu futuro tão promissor tornara-se incerto. Os pais tinham permanecido em Praga com o irmão Franz, tendo seguido depois para Zurique. A situação da família era muito precária. Franz e Lotte decidem-se pelos EUA, Hugo e Dely Perutz juntam-se ao filho em Cambridge. Mas o pior ainda estava por vir.

Numa sucessão rápida, Max e a família são catalogados de "inimigos alienígenas” que, devido ao seu "bom caráter”, podiam permanecer livremente em casa própria; logo, porém, o jovem Perutz é feito prisioneiro. Primeiro esteve detido, juntamente com uma centena de companheiros, em Bury St Edmunds, perto de Cambridge. Depois, em condições cada vez mais precárias, esteve em Huyton (perto de Liverpool) e em Douglas, na Ilha de Man no Mar da Irlanda. Retorna ao continente, onde é imediatamente embarcado no navio H.M.T. Etrick rumo ao Canadá. Condições deploráveis! Esteve gravemente doente, mas sobreviveu.

Por insistência dos pais, de Bernal e de Bragg, e o empenho de Linus Pauling (1901-1994; Prémio Nobel da Química em 1954; Prémio Nobel da Paz em 1962) e de Martin Buerger (1903-1986) que o requisitam para o CalTech e o MIT, respetivamente, Max regressa a Inglaterra em janeiro de 1941, decorridos dez meses de infortúnio.

"Ser preso, internado e deportado como um inimigo estrangeiro pelos ingleses, que eu sempre vi como meus amigos, feriu-me mais do que a própria perda de liberdade”, escreverá Perutz. Mas Cambridge, o Laboratório Cavendish, a sua casa... é onde ele deseja viver. Não suficiente, Max Perutz deseja mesmo contribuir para o esforço de guerra britânico. A oportunidade surgiu com o projeto "Habacuque".

O projeto "Habacuque" consistia no estudo das potencialidades da estrutura do gelo para construção de uma base de aterragem de aviões no meio do Atlântico. Perutz combinava a sua competência de químico com a de glaciologista; era o homem indicado. Para tal, liderou uma equipa de investigação que trabalhou numa câmara a $-20^{\circ} \mathrm{C}$, no subsolo londrino. O grupo concebeu uma mistura de gelo e polpa de madeira, o "pykrete”, tão resistente quanto o betão. O plano, considerado imperioso para a segurança mundial, foi entretanto abandonado. Os elevadíssimos custos de construção e o oferecimento dos aeroportos dos Açores por Portugal ditaram a sua dispensa.

Perutz regressou à hemoglobina, cerca de 10000 átomos, e à sua estrutura 3D. Mas, enquanto aguardamos pela descoberta do efeito da "substituição isomórfica” no desvendar estrutural de macromoléculas, podemos assistir ao encontro de Max e Gisela.

\section{Estabilidade emocional}

Depois dos duros tempos de aprisionamento, Max vai ser feliz. Numa passagem pela Society for the Protection of Science and Learning, ao tempo sediada em Cambridge, é recebido por "uma linda rapariga”, a alemã Gisela Peiser (1915-2005). Gisela, os pais e o irmão tinham trocado Berlim por Zurique, aquando da subida de Hitler ao poder em 1933. Depois, os dois irmãos tinham rumado a Inglaterra. O rapaz estudava na Universidade de Cambridge e Gisela trabalhava na Sociedade como escriturária e tradutora. "Já estava apaixonado por ela ainda antes de sair”, confessará Max. E foi correspondido: "Ele tem uma maravilhosa mistura de inteligência, sensibilidade e entusiasmo”, escreveu Gisela numa missiva aos pais.

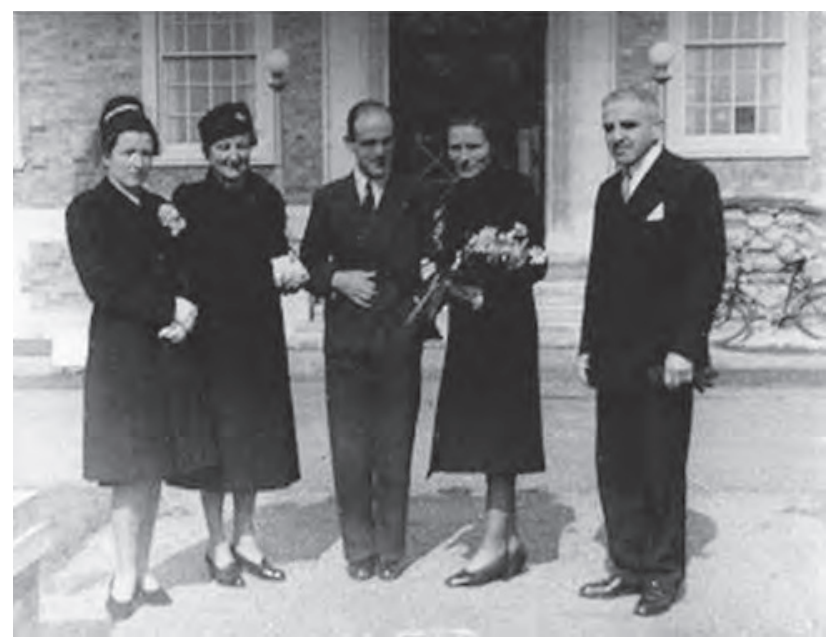

Figura 4 - Fotografia do casamento de Max Perutz e Gisela Peiser (ladeados pelos pais de Max e uma amiga de família). Cortesia de Vivien Perutz.

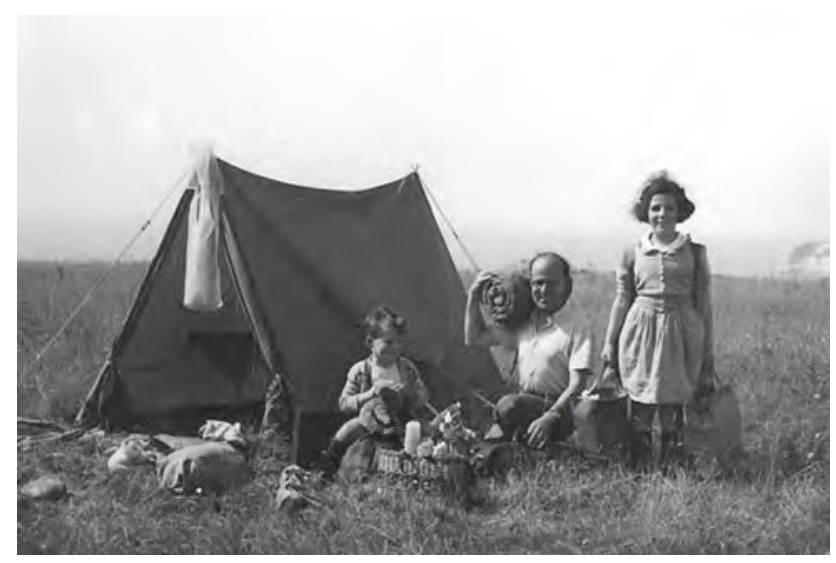

Figura 5 - Max Perutz com os filhos Robin e Vivien. Cortesia de Vivien Perutz.

Casaram na Shire Hall, em Cambridge, com votos cumpridos para todo o sempre. Partilhavam o gosto pelos livros, pela música clássica, pelas pessoas, pelos espaços ao ar livre... Gisela teve o dom de proporcionar a Max um 
verdadeiro lar. Os seus constantes problemas de saúde, psicossomáticos ou não, atenuaram-se. O casal teve dois filhos: em 1944 nasceu Vivien Angela e, cinco anos depois, Robin Noel.

\section{Hemoglobina - a revelação}

Foi em 1953 que Max Perutz teve a ideia crucial de aplicar "substituição isomórfica” ao estudo de moléculas proteicas, e à hemoglobina em particular. Neste método, um ou mais átomos do cristal em estudo são substituídos por outros sem significativa adulteração da estrutura cristalina. A comparação das alterações na intensidade das manchas registadas nos mapas de densidade eletrónica, com ou sem substituição, veio permitir uma compreensão estrutural detalhada. Os átomos pesados - mercúrio foi o eleito de Perutz para a hemoglobina - funcionam como "marcadores" de determinadas regiões da molécula [9].

Entretanto, tinha decorrido uma década de trabalho intenso com resultados nulos. E mais seis anos virão ainda. Em 1949, Max decidira propor uma estrutura para a molécula da hemoglobina: formas cilíndricas achatadas, contendo segmentos de hélice alfa, dispostas em camadas; ficou conhecido pelo nome de "hatbox model" - o modelo da caixa de chapéus. Dentro da "caixa” enrolavam-se quatro camadas de cadeias proteicas paralelas. John Kendrew (1917-1997), o distinto colega que partilhou com Perutz o Prémio Nobel da Química, “viu” a sua mioglobina como discos, de tal modo que quatro discos empilhados constituiriam a hemoglobina... Pura especulação!
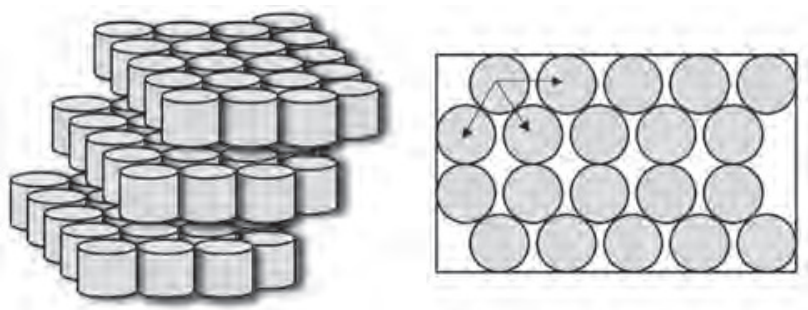

Figura 6 - Modelo “hatbox” da hemoglobina proposto por Perutz (1949)

Foi no decurso de um seminário no Laboratório Cavendish que o modelo foi apresentado. Na assistência, o diretor Lawrence Bragg e os convidados Desmond Bernal, Dorothy Hodgkin (1910-1994; Prémio Nobel da Química em 1964) e William Astbury, entre outros. Mas eis que Francis Crick (1916-2004; Prémio Nobel da Fisiologia ou Medicina em 1962), então estudante de doutoramento de Perutz, demonstra, conclusivamente, que tal abordagem era impossível [10]. Tinha razão.

Finalmente, em 1959, com o precioso auxílio da substituição isomórfica e apurados colaboradores, a estrutura tridimensional da macromolécula biológica hemoglobina, com fraca resolução ( $\approx 5 \AA$ ), dá-se a conhecer [11]; também a mioglobina, menos complexa, é decifrada por John Kendrew e colaboradores (resolução: $2 \AA$ ).

A hemoglobina estudada era de cavalo, mas Perutz adianta que as hemoglobinas de todos os vertebrados devem seguir idêntico modelo. A forma exterior da molécula, um tetrâmero, é aproximadamente esferoide. Quatro iões $\mathrm{Fe}^{2+}$ encontram-se combinados com protoporfirinas de forma a constituírem quatro grupos heme. Perutz admite ain- da que os grupos heme "podem mesmo desempenhar um papel importante na transição entre as formas reduzida e oxigenada” da hemoglobina.

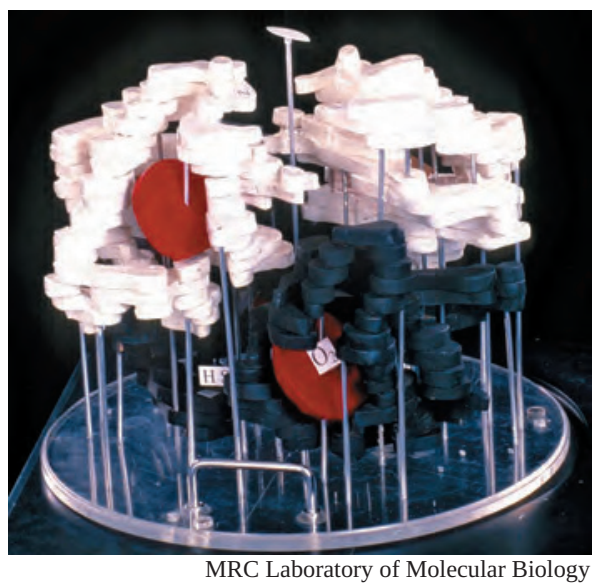

Figura 7 - Modelo da hemoglobina (1959).
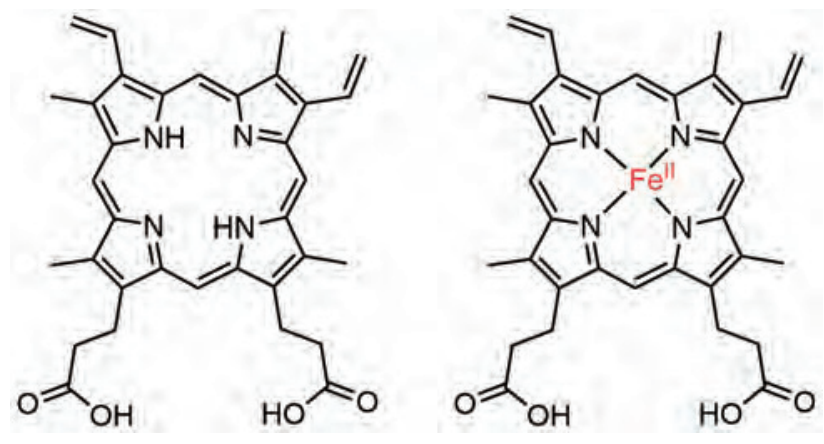

Figura 8 - Estruturas da protoporfirina IX e do heme b.

Os grupos heme rodeiam-se de quatro cadeias polipeptídicas (globina), de tamanho semelhante e iguais duas a duas. Nelas se podem identificar "hélices $\alpha$ " e "folhas $\beta$ ”, tal como Linus Pauling as descrevera. Cada ião central tem seis locais de coordenação, quatro deles ocupados pelos nitrogénios da porfirina e um quinto ligado covalentemente ao aminoácido histidina. É a sexta posição de coordenação que permite a ligação a pequenas moléculas, como seja a de oxigénio, formando a tão útil oxi-hemoglobina.

Max Perutz vai mais longe e aponta a semelhança existente entre a forma como se dobram as quatro cadeias da hemoglobina e da mioglobina, o que, a seu ver, se pode explicar através de (i) uma sequência de aminoácidos semelhante, (ii) configuração espontânea das cadeias satisfazendo os requisitos estereoquímicos do encadeamento das suas unidades, (iii) origem evolutiva comum e (iv) relação direta entre estrutura e função. Se atendermos a que, na época, era desconhecida a estrutura primária destas proteínas, podemos entender quão longe foi a previsão de Perutz.

O Prémio Nobel da Química em 1962, partilhado igualmente por Perutz e Kendrew, "pelos seus estudos das estruturas das proteínas globulares” veio galardoar um grande feito de grandes cientistas. Quando a notícia da atribuição chegou ao laboratório, Perutz foi presenteado com uma salva de palmas, um cavalo de brinquedo e uma garrafa contendo sangue...

Perutz não ficou por aqui. Mostrou que as proteínas podiam alterar a sua estrutura. A comprovação passou 
pela obtenção das estruturas 3D da oxi-hemoglobina e da desoxi-hemoglobina com uma resolução elevadíssima. O oxigénio desencadeava uma série de pequenas, mas significativas, alterações no arranjo dos átomos na molécula. Os modelos, com finura de detalhe, surgiram em 1968-1970 [12]. "Um dos mais importantes mecanismos biológicos do mundo”, assim o descreveu Aaron Klug (n. 1926; Prémio Nobel da Química em 1982).

Uma estreita colaboração com o médico e bioquímico Hermann Lehmann (1910-1985) permitiu a identificação de várias hemoglobinas anómalas. Foram detetados mais de uma centena de "erros" nas posições que explicavam propriedades atípicas e sintomas clínicos. Foi um trabalho delicado e de grande relevância [13]. Perutz interessou-se pela coordenação de ligandos à hemoglobina; este estudo levou ao desenvolvimento de fármacos clinicamente úteis para aumentar a prestação de oxigénio na hipóxia tumoral, na terapia de radiação e na regeneração de tecidos danificados por enfarte. Algumas das suas ideias sobre o mecanismo de atuação da hemoglobina vieram a ser reformuladas pelo avanço da ciência. Usando as próprias palavras de Max Perutz, "In science, truth always wins".

\section{Laboratory of Molecular Biology}

Em 1947 fora criada, no Laboratório Cavendish, uma minúscula unidade de investigação - Medical Research Council Unit for Molecular Biology - para o estudo da estrutura molecular de sistemas biológicos, tendo Max Perutz por diretor e Kendrew como colaborador. No ano seguinte, a Unidade integra o aluno de doutoramento Hugh Huxley (1924-2013) e em 1949 Francis Crick. A MRC Unit, altamente interdisciplinar, foi um fenómeno de atração de cientistas, entre os quais James Watson (n. 1928; Prémio Nobel da Fisiologia ou Medicina em 1962), Vernon Ingram (1924-2006), Sydney Brenner (n. 1927; Prémio Nobel da Fisiologia ou Medicina em 2002), Jerry Donohue (1920-1985), Alexander Rich (1924-2015), Michael Rossmann (n. 1930), Howard Dintzis... e mesmo Peter Pauling (1931-2003), o filho de Linus Pauling. O espaço disponível tornara-se insuficiente.

Um novo e moderno laboratório abriu em 1962, tendo por chairman Max Perutz. Chamou-se MRC - Laboratory of Molecular Biology (LMB). Dispunha de três divisões, com larga autonomia: "Estudos Estruturais”, “Genética Molecular” e “Química das Proteínas”. Um Conselho de Administração constituído pelos chefes das três divisões e o chairman zelava pelo bom funcionamento geral. Quando foi inaugurado os cientistas eram cerca de 40; mas este número aumentou rapidamente com o afluxo de visitantes pós-graduados e alunos de doutoramento. O padrão de qualidade da pesquisa no LMB foi sempre elevado [14].

Max opôs-se à existência de máquinas de café ou chá nos gabinetes e insistiu numa cafetaria, lugar de convívio por excelência; certo é que os cafés sempre foram, ao longo da história, locais aglutinadores de novas ideias científicas. De forma voluntária, sem auferir qualquer salário, Gisela Perutz encarregou-se do seu funcionamento.

Max Perutz foi chairman do LMB até 1979. Depois, sempre conservou espaço laboratorial, gabinete e financiamento para as suas pesquisas!

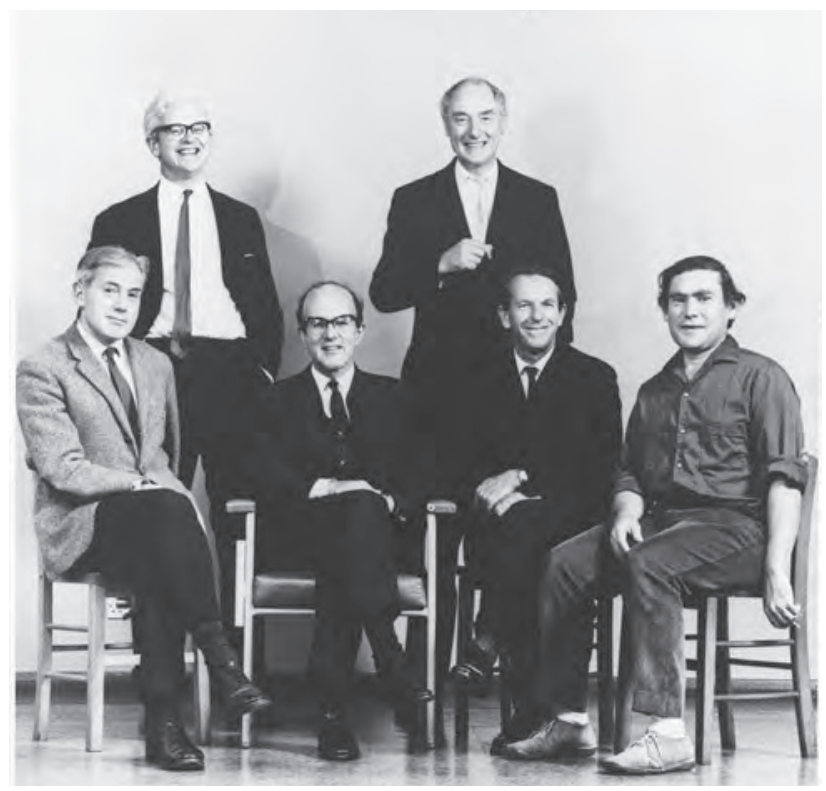

Figura 9 - Conselho de Administração do LMB (1967). Da esquerda para a direita: Hugh Huxley, John Kendrew, Max Perutz, Francis Crick, Fred Sanger e Sydney Brenner.

\section{Deixe-me dizer-lhe...}

Max Perutz foi convidado pelo Repository for Germinal Choice a ser um dador de esperma. Assim respondeu: "Let me tell you... que sou baixo, careca, míope e vesgo, que os meus testículos foram expostos aos raios X durante 44 anos... e que sou atormentado por múltiplas alergias e afetado por problemas nas costas. Isto mostra que a conquista do Prémio Nobel não significa necessariamente que acompanhe outras características genéticas desejáveis”. Colegas e amigos sempre consideraram excessivos os cuidados de Max com a sua saúde. Eram as suas excentricidades, “The Nobel Art”... Mas as dores no peito que sentiu, ia pelos 85 anos, eram bem reais; um bypass e um pacemaker aliviaram a situação e restituíram-no à investigação e às viagens à Europa e aos EUA.

Em 2001, uma aparente verruga teve um diagnóstico calamitoso: carcinoma de células de Merkel. Max tinha apenas algumas semanas de vida. A intensa exposição aos raios solares nas espetaculares subidas às montanhas terá sido influência marcante. Sereno, muito sereno... "Tive 65 anos de uma pesquisa científica fantasticamente produtiva e um casamento feliz, filhos e netos encantadores que me rodearam de carinho e finalmente desfrutei da amizade de tanta gente maravilhosa”, escreveu ele.

Perutz manteve uma convivência sempre cordial com personagens tão diferentes e complexas quanto Lawrence Bragg, John Kendrew ou Francis Crick. Uma grande afeição, e admiração, unia-o a Desmond Bernal e a Dorothy Hodgkin. Quando esta desvendou a estrutura da insulina, Max Perutz foi a Oxford felicitá-la. Disse então que, se o governo britânico decidisse conferir títulos nobiliários, ele provavelmente chamar-se-ia “Lord Hemoglobina”, John Kendrew "Lord Mioglobina” e Dorothy seria, simultaneamente, "Lady Colesterol”, “Lady Penicilina”, “Lady Vitamina $B_{12}$ ” e “Lady Insulina”! [15,16]. Mas Perutz tinha também "inimigos científicos”, os cientistas que criticaram alguma das suas propostas de estrutura e dinâmica da mo- 
lécula da hemoglobina, a “sua” molécula; com estes podia ser mesmo descortês.

Legou-nos ensaios e revisões, escritos com espírito arguto e original, que vieram a ser publicados em livro. Citamos: "That Was the War: Enemy Alien" (1985), "Is Science Necessary? Essays on science and scientists" (1989), "Science is Not a Quiet Life: Unravelling the Atomic Mechanism of Haemoglobin" (1997) e "I Wish I'd Made You Angry Earlier" (1998).

Recebeu muitas honras e prémios. Entre eles, a Royal Medal (1971) e a Copley Medal da Royal Society (1979), a Pour Le Mérite (1987) e a Order of Merit (1988) [17]. Em 1997 foi-lhe atribuído o prémio literário Lewis Thomas Prize "em reconhecimento do cientista como poeta".

\section{Agradecimento}

A Vivien Perutz, historiadora de arte (Universidade de Cambridge) e a Robin Perutz, professor de química (Universidade de York), filhos de Max Perutz, pela amável disponibilização de algumas fotografias que ilustram este artigo.

\section{Referências}

[1] G. Ferry, "Max Perutz and the Secret of Life", Chatto \& Windus, Londres, 2007.

[2] R. Gonçalves-Maia, "Perutz”, Série "Dos Átomos e das Moléculas”, n. ${ }^{\circ}$ 5, LF Editorial, São Paulo, 2017.

[3] K. Crick, "What Mad Pursuit: A Personal View of Scientific Discovery”, Basic Books, EUA, 1988.

[4] Tanto a família do pai como a da mãe de Max Perutz eram fabricantes de têxteis, com fortuna alicerçada na introdução mecanizada de fiação e tecelagem; o filho mais velho, Franz Perutz, fez estudos técnicos de engenharia na Suíça a fim de trabalhar no desenvolvimento da indústria familiar.
[5] R. Gonçalves-Maia, QUÍMICA - Boletim SPQ (142) (2016) 35-39.

[6] R. Gonçalves-Maia, "Bernal”, Série "Dos Átomos e das Moléculas”, n. ㅇ 3, LF Editorial, São Paulo, 2016.

[7] A metemoglobina difere da hemoglobina por o seu grupo heme conter $\mathrm{Fe}^{3+}$ ao invés de $\mathrm{Fe}^{2+}$, não podendo, por isso, ligar o oxigénio.

[8] J.D. Bernal, I. Fankuchen, M. Perutz, Nature 141 (1938) 523-524.

[9] D.W. Green, V.M. Ingram, M.F. Perutz, Proc. R. Soc. Lond. A 225 (1954) 287-307

[10] É conhecida a aversão de Lawrence Bragg pela personalidade efusiva de Crick. Imagine-se o estado em que ficou perante o atrevimento deste em desdizer um investigador sénior numa seleta audiência. Sobre o seu ombro, segredou-lhe: "You are rocking the boat"...

[11] M.F. Perutz, M.G. Rossmann, A.F. Cullis, H. Muirhead, G. Will, A.C.T. North, Nature 185 (1960) 416-422.

[12] M.F. Perutz, Nature 228 (1970) 726-734.

[13] M.F. Perutz, H. Lehmann, Nature 219 (1968) 902-909.

[14] Um novíssimo LMB foi inaugurado em 2013, integrado no Cambridge Biomedical Campus.

[15] Testemunho de M. Vijayan, presidente do Conselho de Investigação do Indian Institute of Chemical Biology, em [16].

16] R. Gonçalves-Maia, "Dorothy Crowfoot Hodgkin - Pepsina, Penicilina, Colesterol, Vitamina $B_{12}$, Insulina”, Edições Colibri, Lisboa, 2010.

[17] É curioso que, durante alguns anos, entre os detentores da Order of Merit, insígnia real que apenas 24 membros honorários vivos do Reino Unido podem possuir simultaneamente, se contavam dois químicos: Perutz e Hodgkin.

\section{Submit to your society's journals} www.chempubsoc.eu
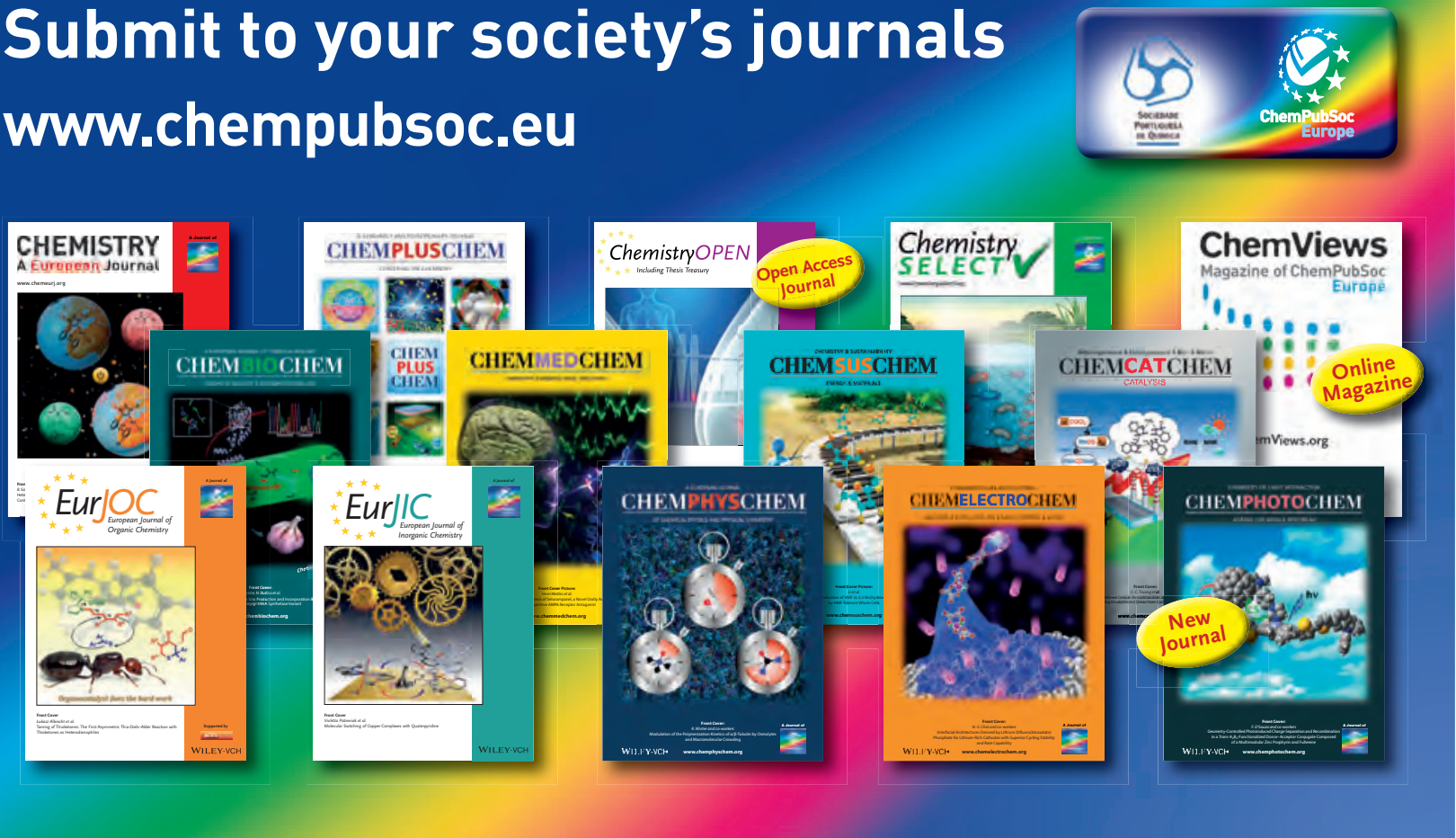